MS33 Hot structures of small molecules

\section{MS33-P1 Syntheses and crystal structures of transition-metal bromide complexes with pyridine-type ligands: $\left[\mathrm{MBr}_{2}(3 \text {-cypy })_{4}\right]$ and $\left[\mathrm{MBr}_{2}(3-\text {-урy })_{2}\right]_{\mathrm{n}}$ \\ Miriam Heine ${ }^{1}$, Lothar Fink ${ }^{1}$, Martin U. Schmidt ${ }^{1}$}

1. Goethe-Universität Frankfurt am Main, Institut für Anorganische und Analytische Chemie, Max-von-Laue-Straße 7, 60438 Frankfurt am Main, Germany

email: miriam.heine@t-online.de

In recent years numerous investigations on the syntheses and structural characterization of new coordination polymers based on transition-metals have attracted much attention due to their useful physical properties and their various potential applications [1]. We report the crystal structures of the ternary mixed complexes $\left[\mathrm{MBr}_{2}(3 \text {-cypy) }]_{4}\right.$ and thermal intermediates $\left[\mathrm{MBr}_{2}(3 \text {-cypy })_{2}\right]_{1}$, with $\mathrm{M}^{\mathrm{II}}=\mathrm{Co}, \mathrm{Ni}$, formed during decomposition. All crystal structures were determined by $\mathrm{X}$-ray powder diffraction. In the ligand rich compounds the metal atoms are octahedrally coordinated by two bromide anions in trans-position and by four nitrogen atoms of the neutral co-ligands in order to build up discrete molecules (Fig. 1). Thermal decomposition induces the polymerization of these molecules: by release of two cyanopyridine molecules in the first step of thermal decomposition single chains are obtained where the $\mathrm{M}^{\mathrm{II}}$-ions are linked by pairs of bridging bromide cations in order to maintain the octahedral coordination at the metal atom. Further decomposition steps lead to the formation of double chains, bands and larger two dimensional networks [2], [3].

\section{References:}

[1] Batten et al., Pure Appl. Chem 85, 1715, 2013

[2] Krysiak et al., ZAAC 640, 3190, 2014

[3] Zhao et al., 2015 in preparation

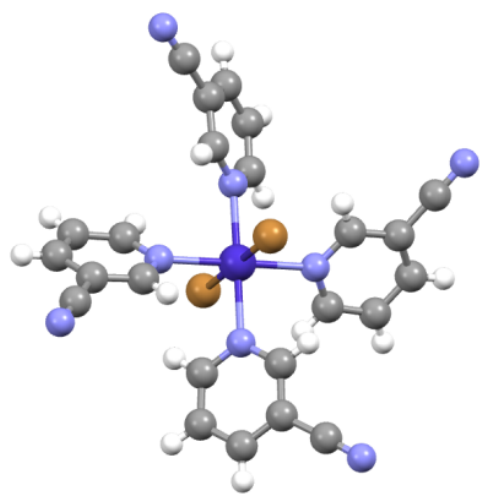

Figure 1. Molecular structure of the ligand rich precursor compound

Keywords: X-ray powder diffraction, crystal structures, structure relations, coordination polymers, condensed networks, substituted pyridine ligands, transition-metal halides 